\title{
Inter-related Factors Influencing Sexual Quality of Life among Women Living with HIV in Banten Province, Indonesia: A Mixed Methods Study
}

\author{
Dyah Juliastuti ${ }^{1,2 *}$, Judith Dean ${ }^{1}$, Yati Afiyanti ${ }^{3}$, Lisa Fitzgerald ${ }^{1}$
}

\begin{abstract}
${ }^{1}$ School of Public Health, Faculty of Medicine, University of Queensland, Queensland, Australia
${ }^{2}$ Nursing Program, Sekolah Tinggi Ilmu Kesehatan Ichsan Medical Centre Bintaro, South Tangerang, Indonesia

${ }^{3}$ Department of Women's Health and Maternity Nursing, Faculty of Nursing, Universitas Indonesia, Depok, Indonesia
\end{abstract}

\begin{abstract}
Socio-cultural concerns often restrict women's sexual rights and well-being living with HIV (WLHIV) in developing countries. These convergent parallel mixed methods study combined quantitative and qualitative approaches to explore factors influencing WLHIV sexual quality of life in Banten Province, Indonesia. A 2017 cross-sectional survey of 207 reproductive-aged WLHIV was analyzed using univariate and multivariate logistic regression statistics. Furthermore, indepth interviews with a sub-sample of survey participants $(n=30)$ were thematically analyzed. Most of the women $(60 \%)$ involved reported loss of sexual pleasure and depressed sexual life. Meanwhile, $48 \%$ affirmed low sexual quality of life which was associated with unemployment $(\mathrm{aOR}=2.90$, and $95 \% \mathrm{Cl}=$ 1.51-5.58), limited sexual activities $(\mathrm{aOR}=2.89$, and $95 \% \mathrm{Cl}=1.20-6.93)$, living with extended family $(\mathrm{aOR}=2.68$, and $95 \% \mathrm{Cl}=1.27-5.65)$, and experiencing intimate partner violence $(\mathrm{aOR}=2.28$, and $95 \% \mathrm{Cl}=1.03-5.03)$. The respondents described unsatisfactory sexual life in a belief that having sex is a wife's duty and choosing not to talk about sexual issues or refuse sexual invitation in fear of triggering intimate partner violence. Inter-related personal, social, cultural, and religious factors affected the sufferers' sexual life.
\end{abstract}

Keywords: HIV, mixed-methods, sexual life, women

\section{Introduction}

In 2019, approximately 300,000 new human immunodeficiency virus (HIV) cases were detected, bringing the number of people living with HIV (PLHIV) in the AsiaPacific region to 5.8 million. ${ }^{1}$ In the same year, an additional 50,300 were reported, making 641,700 PLHIV in Indonesia. ${ }^{2}$ New HIV cases proportion among this county's women is lower than men $(35.5 \%$ vs $64.5 \%)$. However, new women cases have been more than doubled from 8,300 in 2010 to 17,800 in $2019 .^{3}$

Banten has the eighth highest cases of new HIV infection among 34 provinces in Indonesia because there was a four-fold increase in the diagnoses rates from 433 in 2011 to 1,600 in $2019 .^{2}$ According to 2019 National Indonesian acquired immunodeficiency syndrome (AIDS) data, the dominant occupations of the newly diagnosed women were non-professional employees $(1,800)$, housewives $(1,100)$, and entrepreneurs $(752)$, while the sex workers (113) were historically identified to be at risk. Over the past decade, AIDS cases among housewives have also notably increased, ${ }^{3}$ suggesting possible prevalence of late diagnosis among this population.

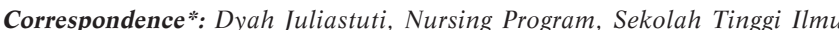
Kesehatan Ichsan Medical Centre Bintaro, Jombang Raya Street No. 56, Ciputat, South Tangerang, Banten, Indonesia, Email: d.juliastuti@uqconnect.edu.au, Phone: +62 81319382704
Respecting the sexual and reproductive health (SRH) rights of women living with HIV (WLHIV) is crucial for improving their dignity, health, and wellbeing, ${ }^{4}$ as postulated by United Nations Population Fund (UNFPA), 5 "... able to have a satisfying and safe sex life, the capability to reproduce, and the freedom to decide if, when, and how often to do so". When women express their SRH needs and rights, they attain better SRH and lower risk of ill-health. ${ }^{6}$ Supporting these also contribute of eliminating the worldwide HIV epidemic along with reducing onwards transmission of other sexually transmitted infection (STI) and negative SRH outcomes.

Post-HIV diagnosis, varied bio-socio-cultural determinants lead to women experiencing less active and satisfying sexual lives. According to the past reviews, HIV disclosure removes sexual desire, intimacy, and satisfaction among WLHIV. 7,8 Some PLHIV fear infecting their partner/s, feel guilty for having sex, and also struggle to talk about sexual topics. ${ }^{9}$ The high prevalence of sexual inactivity among WLHIV is influenced by HIVrelated stigma, being single, and low-income status. ${ }^{10}$ Some WLHIV, particularly young and unmarried, feel

Received : March 08, 202

Accepted : April 13, 2021

Published: May 28, 2021 
forced to be sexually abstinent to prevent HIV transmission. ${ }^{11}$ Social structures leading to gender inequalities, economic powerlessness, and disproportionate health burdens experienced by many women when combined with an HIV diagnosis increase the risk of living in abusive marriages and further restrictions to sexual and reproductive rights. ${ }^{12-14}$

A systematic literature review exploring the SRH of WLHIV in Muslim-majority countries found that after diagnosis, the women experience disappointment towards their sexual life, including stressful intimacy. ${ }^{15}$ However, there has been limited examination of Indonesian WLHIV sexual life and satisfaction. Therefore, this mixed-methods study aimed to explore the multiple factors influencing WLHIV sexual quality of life in Banten Province, Indonesia. It was conducted as part of a pilot project entitled 'The Sexual and Reproductive Health of WLHIV in Banten Province, Indonesia'. A more contextualized understanding of these women's sexual lives is expected by combining quantitative and qualitative approaches. ${ }^{16,17}$ Contextualizing the social, cultural, and religious determinants of WLHIV's sexual life is important for supporting SRH needs and rights. Furthermore, the invaluable understanding informs a development of much-needed appropriate and acceptable SRH health policy and strategies in preventing further HIV/STI transmission, intimate partner violence (IPV), and unplanned pregnancy.

New HIV cases high rates and increasing numbers of WLHIV in Indonesia, particularly in Banten province, supports the urgent need to understand the personal, social, cultural, and social caveats affecting WLHIV's sexual life since sexual dysfunction impacts women's reproductive outcomes, life quality, and further HIV transmission. Therefore, the objectives of this study were to carry out the following, (1) explore demographic characteristics, clinical history, sexual activities, and SQoL of the WLHIV; (2) analyze multiple factors associated with their sexual life quality; and (3) describe the inter-related factors contributing to the sexual life quality.

\section{Method}

A convergent parallel mixed-method study, combining a cross-sectional survey with in-depth interviews, involving WLHIV of reproductive age (18-50-year-old) living in Banten Province, was conducted from June to November 2017. The quantitative and qualitative data collection, analysis, and interpretation were performed concurrently to reveal convergence, supporting evidence, and validation. ${ }^{18,19}$ The WLHIV used as participants went for treatment in four public and one private hospital, as well as four primary health cares in Banten Province. They were recruited by five trained peer recruiters (PR) providing support for PLHIV that visit local health care services, appointed by the collaborative study partner, Yayasan Kotex Mandiri. Yayasan Kotex Mandiri is a local non-governmental organization that provides care and support for PLHIV in DKI Jakarta and Banten Province through individual or group peer-accompaniment. The PRs were women with a minimum of high school education and trained on approaching the potential participants ethically and assist them in completing questionnaire.

The cross-sectional survey applied convenience and a snowball sampling to recruit 207 WLHIV of reproductive age (18-50-year-old) living in Banten Province and had a current or past history of sexual activity. Based on a target population of 1,721 WLHIV in the region in 2015,20 the required sample size was estimated to be 315. ${ }^{21}$ However, this minimum size was not achieved during six-month data collection as the available budget and timeframes were limited. After signing the informed consent, the participants completed an Indonesian version of a self-administered paper-based questionnaire with the PRs assistance. Each survey was conducted within 30 minutes in the place chosen by the women.

Quantitative data were collected using a structured questionnaire first prepared in English, then translated to Indonesian. The instrument was designed using items from the Women's Health questionnaire (WHQ) of the 2012 Indonesia Demographic and Health Survey (IDHS), 22 and the Sexual Quality of Life-Female (SQoLF) questionnaire, ${ }^{23}$ that adjoined questions about WLHIV demographic characteristics and HIV-clinical histories. The WHQ sought information on varied topics of women's SRH, including HIV, reproductive behaviors and intentions, as well as other sexually transmitted infections. Meanwhile, the SQoL-F was developed by Symonds and colleagues, ${ }^{24}$ to measure women sexual dysfunction.

The survey instrument included 12 demographic characteristics variables (age, educational background, place of residence, religion, occupation, marital status, family income, and main source of income) and clinical histories (partner's HIV status, diagnosis time and knowledge, as well as infection source). This also contains eight sexual activities variables (first sexual encounter, number of lifetime sexual partners, last sexual intercourse, sexual-intimate partner violence (IPV) history, sexual activities, number and type of sexual partners in the past 12 months, and condom use) extracted from the WHQ- 2012 IDHS. Eighteen variables related to sexual quality of life from the SQoL-F scale were added. Each SQoL-F item has a six-point response (completely agree to completely disagree) and is scored 1-6. A total sexual quality of life (SQLL) score (0-100) was calculated according to an algorithm ([unstandardized score$18]^{*} 100 / 90$ ) used for the initial questionnaire analysis, 
with a higher score indicating a better sexual quality of life. ${ }^{23}$ A low SQoL was defined as an SQoL-F score below the average, and vice versa. SQoL-F reliability analysis was conducted to ascertain whether it was reliable for Indonesian women and yielded a Cronbach's alpha of 0.89 , which shows the questionnaire reached an acceptable internal consistency. 24,25

Survey data were analyzed using statiscal software set up in University of Queensland computer for the staff and research students. Initially, all dependent and independent variables were presented in percentages and mean/standard deviation (SD). A binary logistic regression model, in which variables were set to be dichotomous, was used to assess the univariate and multivariate relationships between independent and dependent variables (SQoL). The categorical/dichotomous variables were compared using Pearson Chi-square for the univariate analysis. After testing for interaction effects and multicollinearity, multiple risk variables indicating a univariate association with the outcome variables ( $p$-value < 0.10 ) were entered into a multivariate logistic regression to obtain significant risk factors for low SQoL (p-value < 0.01 or p-value $<0.05$ ). A p-value with a cut-off point of $<0.10$ was used to identify potential predictors rather than to test a hypothesis. 24,25

To anticipate inconsistent and contradictory data and ambiguous health behaviors, ${ }^{26,27}$ this study supplemented the survey data with qualitative in-depth interviews conducted for 30 WLHIV sub-sample of reproductive age (18-50-year-old). The interview participants were purposively sampled from those used for the survey to select various persons reflective of the target population demographics and experiences. The in-depth interviews were conducted individually and privately at the survey recruitment sites or in an alternate setting of the participant's choice. The interviews were directed following a semi-structured guide designed by the authors team in the planning phase and which on average took approximately one and a half hours to complete. The interviews were conducted in Indonesian by the first author that has extensive experience and speaks this language. The interviews were digitally recorded and transcribed verbatim, translated into English, coded, and thematically analyzed using qualitative data analysis software.

The thematic analysis involved several recursive phases suggested by Braun and Clark. ${ }^{28}$ First, the study team tried to be familiar with the collected data by reading them several times and writing the initial impression had. Then, initial codes were generated and similar ones were collated into tentative themes. All data was gathered according to the potential themes and the developed themes were reviewed and revised until data saturation was reached and a study report was finalized.16,29 The consistency of the codes and the contextualized themes were checked by the other two members that were experts in qualitative study and SRH issues. The qualitative analyses used pseudonyms (an unreal name chosen by the participants) to respect confidentiality in the final results presentation. This data collection's credibility was ensured by having an experienced and trained interviewer, opening access of the audio recording for other author members when necessary, and conducting probing to elicit vague or ambiguous responses. ${ }^{30}$

Last, the quantitative and qualitative data were compared, converged, and interpreted. Similar or different inferences were synthesized and organized into a joint display of women's sexual wellness. ${ }^{31}$ The survey results were compared using qualitative data side-by-side to confirm or disconfirm similarities and enrich the explored phenomenon. This convergent process yielded a deeper final interpretation. The University of Queensland Ethics Committee (no. 2017000354) granted the ethics approval for this study in May 2017. A local study permit was given by the Yayasan Kotex Mandiri, as a partner, and the National Unity and Politics Agency of Banten Provincial Government.

\section{Results}

Out of the 207 survey participants, most were in their thirties $(60.8 \%)$. The majority had completed primary school $(88.4 \%)$, were living in an urban area $(79.7 \%)$, Muslim $(87.4 \%)$, and had their HIV diagnosis more than one year before the study (61.9\%). Many (54.1\%) were not working, and only $28 \%$ had a HIV-positive partners. About 42 (20.3\%) women did not know their partner's HIV status, and only $33.3 \%$ had disclosed their status. More than $80 \%$ acquired their HIV infection from heterosexual contact (Table 1).

Table 2 illustrates the average age of first sexual intercourse was 20.8 years, with the earliest encounter occurring at 12 years. More than half reported having beyond one sexual partner in their lifetime and had last sexual intercourse within the past four weeks. Less than onethird reported using a condom consistently during sexual intercourse in the past 12 months and also experiencing sexual-IPV. Most of the $171(82.6 \%)$ participants with current sexual activities stated they had sexual intercourse with only one person $(78.4 \%)$, particularly their husband $(74.9 \%)$.

Most of the 207 participants that have been in a sexual relationship reported positive responses on their sexual and relationship satisfaction. Accordingly, 83.6\% thought sex life meant talking to their partner about sexual matters is possible, $79.7 \%$ felt close to their partner, $74.4 \%$ thought sex was an enjoyable part of life, $69.1 \%$ had good self-feeling, and $66.2 \%$ were happy with the sexual activity frequency. Conversely, about two-thirds reported losing pleasure in their sex life $(69.1 \%)$, also 
Table 1. Demographic Characteristics and Clinical Histories of Survey Participants $(\mathbf{n}=\mathbf{2 0 7})$

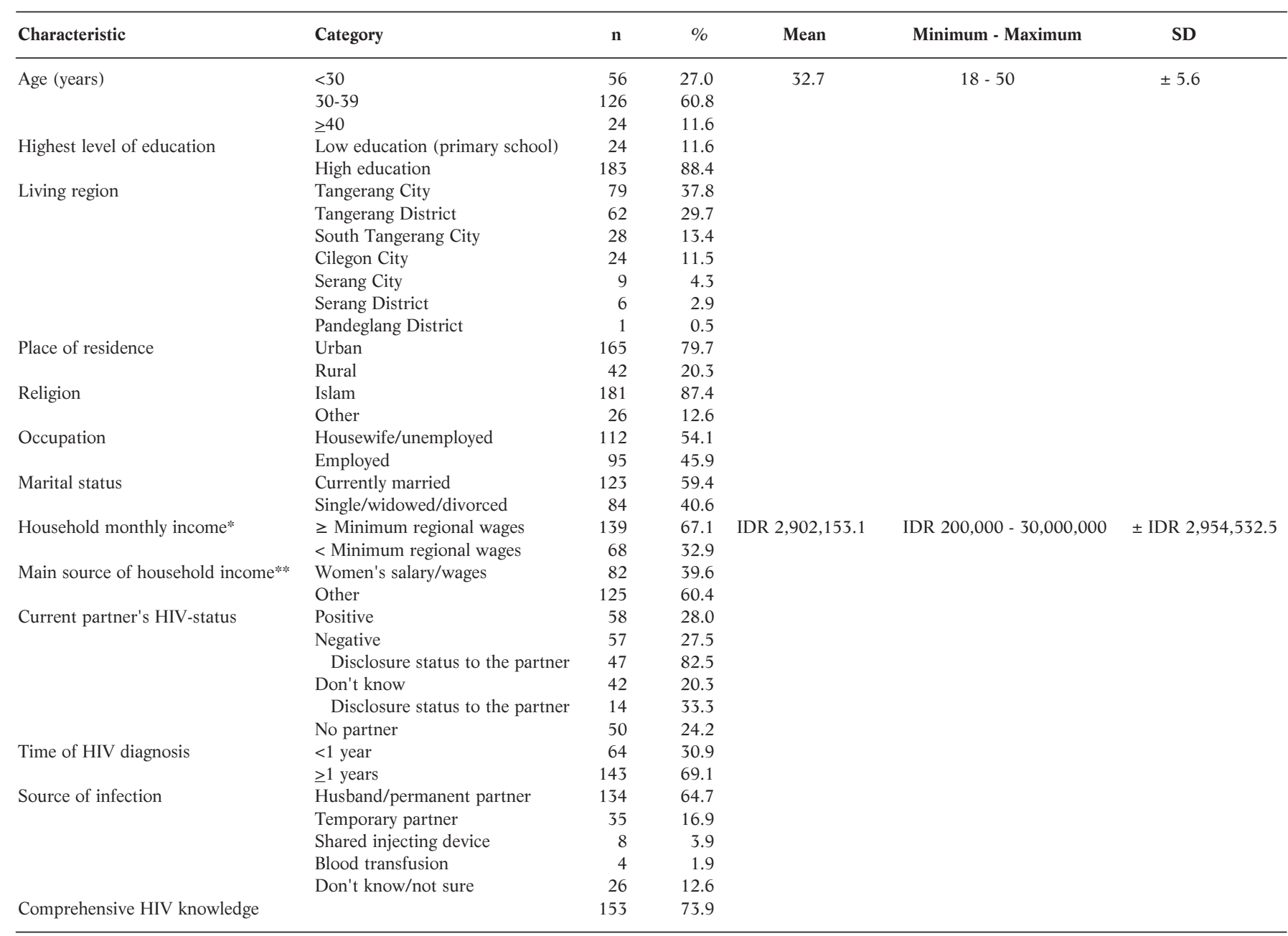

Notes: *Banten Province's minimum regional wage set by the Indonesian Government in 2017 was IDR 1,931,180. The standardized minimum wages in each city/district issued by Banten Provincial Government were: IDR 3,270,936.13 in Tangerang District, IDR 3,295,075.88 in Tangerang City, IDR 3.270.936,13 in South Tangerang City, IDR 3,258,866.25 in Serang District, IDR 3,331,997.63 in Cilegon City, IDR 2,866,595.31 in Serang City, and IDR 2,164,979.43 in Pandeglang District (From https://wageindicator.org/salary/minimum-wage/indonesia/archive/3/).

***Husband/partner, parents, siblings, kids, and/or friends.

$\mathrm{SD}=$ Standard Deviation

felt angry $(66.7 \%)$ and depressed $(64.7 \%)$ about it, and tried to avoid sexual activity $(64.3 \%)$ as thinking about sex made them feel being less of a woman $(60.9 \%)$ (Table 3). The participants' average score of all SQoL components was 56.7 (range: 7-94, SD: \pm 17.4 ), with almost half $(99,47.8 \%)$ reporting low SQoL.

The binary logistic regression was used to assess demographic, clinical, and sexual activity factors that influenced SQoL reported among 207 WLHIV (Table 4). Based on univariate logistic regression result, 13 risk factors contributed to low SQoL, including family monthly income $(\mathrm{cOR}=20.08,95 \% \mathrm{CI}=1.20-3.63$, and $\mathrm{p}$-value $=0.04)$ and living with extended family $(\mathrm{cOR}=2.80$, $95 \% \mathrm{CI}=1.47-5.31$, and $\mathrm{p}$-value $<0.001)$. Multivariate analysis indicated only six factors were significantly asso- ciated with low SQoL. Surveyed participants that were housewives or unemployed and not sexually active in the past year were almost three-fold more liable to have low SQoL than those working $(\mathrm{aOR}=2.90,95 \% \mathrm{CI}=1.51$ 5.58 , and p-value $<0.001)$ and sexually active $(\mathrm{aOR}=$ $2.89,95 \% \mathrm{CI}=1.20-6.93$, and $\mathrm{p}$-value $=0.02)$. Meanwhile, low SQoL significantly related to living with extended family $(\mathrm{aOR}=2.68,95 \% \mathrm{CI}=1.2-5.65$, and $\mathrm{p}$ value $=0.01)$, IPV incidents $(\mathrm{aOR}=2.28,95 \% \mathrm{CI}=$ 1.03-5.03, and p-value $=0.04$ ), lack of understanding about HIV transmission $(\mathrm{aOR}=2.26,95 \% \mathrm{CI}=1.13$ 4.54 , and p-value $=0.02$ ), and on ART for less than a year $(\mathrm{aOR}=2.14,95 \% \mathrm{CI}=1.14-4.03$, and $\mathrm{p}$-value $=$ $0.02)$.

The 30 WLHIV interviewed were aged between 22 
Table 2. Sexual Activities of Women Living with HIV

\begin{tabular}{llrr}
\hline Sexual Activity & Category & $\mathbf{n}$ & $\%$ \\
\hline Age at 1 st sexual intercourse (years) $(\mathrm{n}=207)$ & $<20$ & 89 & 43.0 \\
& $\geq 20$ & 118 & 57.0 \\
Number of lifetime sexual partners $(\mathrm{n}=207)$ & 1 & 87 & 42.0 \\
& $\geq 2$ & 120 & 58.0 \\
Last sexual intercourse $(\mathrm{n}=207)$ & Within the past 4 weeks & 139 & 67.1 \\
& 4 weeks-1 year ago & 32 & 15.5 \\
& $>1$ year ago & 36 & 17.4 \\
Sexual intimate partner violence (IPV) $(\mathrm{n}=207)$ & No & 163 & 78.7 \\
Having sexual activities in the past 12 months $(\mathrm{n}=207)$ & Yes & 44 & 21.3 \\
Number of sexual partners in the past 12 months $(\mathrm{n}=171)$ & 1 & 171 & 82.6 \\
& $\geq 2$ & 134 & 78.4 \\
Sexual partner(s) in the past 12 months $(\mathrm{n}=171)$ & Husband & 37 & 21.6 \\
& Boyfriend not living with me & 140 & 81.9 \\
& Client/sex work & 13 & 12.9 \\
& Casual acquaintance & 5 & 7.6 \\
& Live-in partner & 5 & 2.9 \\
Consistent condom use $(\mathrm{n}=171)$ & Other/not mentioned & 2 & 1.2 \\
& & 54 & 31.6 \\
\hline
\end{tabular}

Table 3. Sexual Quality of Life of Women Living with HIV in Banten Province, Indonesia, 2017 ( $\mathrm{n}=\mathbf{2 0 7}$ )

\begin{tabular}{lrrrr}
\hline & \multicolumn{3}{c}{ Completely/Moderately/Slightly } \\
\cline { 2 - 6 } Sexual Quality of Life Item & \multicolumn{2}{c}{ Agree } & \multicolumn{2}{c}{ Disagree } \\
\cline { 2 - 6 } & $\mathbf{n}$ & $\%$ & $\mathbf{n}$ & $\%$ \\
\hline When I think about my sex life, & & & & \\
I feel that I can talk to my partner about sexual matters & 173 & 83.6 & 34 & 16.4 \\
I feel close to my partner & 165 & 79.7 & 42 & 20.3 \\
It is an enjoyable part of my overall life & 154 & 74.4 & 53 & 25.6 \\
I feel good about myself & 143 & 69.1 & 64 & 30.9 \\
I have lost pleasure in sexual activity & 143 & 69.1 & 64 & 30.9 \\
I feel angry & 138 & 66.7 & 69 & 33.3 \\
I am satisfied with the frequency of sexual activity & 137 & 66.2 & 70 & 33.8 \\
I feel depressed & 134 & 64.7 & 73 & 35.3 \\
I try to avoid sexual activity & 133 & 64.3 & 74 & 35.7 \\
I feel like less of a woman & 126 & 60.9 & 81 & 39.1 \\
I feel frustrated & 122 & 58.9 & 85 & 41.1 \\
I feel guilty & 118 & 57.0 & 89 & 43.0 \\
I feel anxious & 112 & 54.1 & 95 & 45.9 \\
I feel embarrassed & 106 & 51.2 & 101 & 48.8 \\
I have lost confidence in myself as a sexual partner & 104 & 50.2 & 103 & 49.8 \\
I feel like I have lost something & 98 & 47.3 & 109 & 52.7 \\
I worry about the future of my sex life & 93 & 44.9 & 114 & 55.1 \\
I worry that my partner feels hurt or rejected & 89 & 43.0 & 118 & 57.0 \\
\hline
\end{tabular}

and 41 years, among which most lived in urban areas in six cities or regencies of Banten Province. Almost all women were Muslim and had completed high school, while the majority (19) were employed and three had been commercial sex workers. Many were in a marital relationship (20) as can be seen in Table 5 .

The interview data indicated most women were sexually active in the past 12 months. However, over half reported unsatisfying sexual lives post-HIV diagnosis. Most talked about their concerns on maintaining enjoyable sexual relationships as their sexual life was interrupted by the inability to mention personal sexual needs and rights and the intimate partner's violent behavior. The thematic analysis of in-depth interview data generated two themes namely, poor sexual quality and factors influencing SQoL.

Theme 1 . Poor quality of sexual life

The in-depth interview data indicated many participants in a relationship did not report a satisfying sexual life. For many, the changes to their sexual lives occurred after diagnosing their partner had infected them with HIV. Sarah, a 39-year-old housewife, described her disappointment towards the man that had infected her, say- 
Table 4. Univariate and Multivariate Logistic Regression Analysis Assessing Risk Factors of Low Sexual Quality of Life among Women Living with HIV in Banten Province, Indonesia $2017(\mathrm{n}=\mathbf{2 0 7})$

\begin{tabular}{|c|c|c|c|c|c|c|}
\hline \multirow{2}{*}{ Risk Factor } & \multirow{2}{*}{ Category } & \multicolumn{3}{|c|}{ Low SQoL Univariate/Unadjusted Analysis } & \multicolumn{2}{|c|}{ Multivariate/Adjusted Analysis } \\
\hline & & n $(\%)$ & cOR & p-value & aOR & p-value \\
\hline Low SQoL occurrence & & $99(47.8)$ & & & & \\
\hline \multirow[t]{2}{*}{ Occupation } & Housewife/unemployed & $62(55.4)$ & $1.94(1.12-3.39)$ & 0.02 & $2.90(1.51-5.58)$ & $<0.001$ \\
\hline & Employed & $37(38.9)$ & reference & & reference & \\
\hline \multirow{2}{*}{ Marital status } & Single/widowed/divorced & $51(60.7)$ & $2.42(1.37-4.26)$ & $<0.001$ & & \\
\hline & Married & $48(39.0)$ & reference & & & \\
\hline \multirow[t]{2}{*}{ Family monthly income } & $\geq$ Minimum regional wages & $61(56.5)$ & $20.08(1.20-3.63)$ & 0.01 & & \\
\hline & $<$ Minimum regional wages & $38(38.4)$ & reference & & & \\
\hline \multirow[t]{2}{*}{ Main source of income } & Women salary/wages & $48(41.4)$ & reference & & & \\
\hline & Other & $51(56.0)$ & $1.81(1.04-3.15)$ & 0.04 & & \\
\hline \multirow[t]{2}{*}{ Living arrangement } & Alone/with nuclear family & $62(41.1)$ & reference & & reference & \\
\hline & With joint/extended family & $37(66.1)$ & $2.80(1.47-5.31)$ & $<0.001$ & $2.68(1.27-5.65)$ & 0.01 \\
\hline \multirow[t]{2}{*}{ Time on antiretroviral theraphy } & 0 or $<1$ year & $50(58.8)$ & $2.13(1.21-3.74)$ & 0.01 & $2.14(1.14-4.03)$ & 0.02 \\
\hline & $\geq 1$ year & $49(40.2)$ & reference & & reference & \\
\hline \multirow{2}{*}{ HIV status disclosure to the partner } & No & $50(56.2)$ & $1.81(1.04-3.15)$ & 0.04 & & \\
\hline & Yes & 49 (41.5) & reference & & & \\
\hline \multirow[t]{2}{*}{ Pregnancy post-HIV diagnosis } & No & $58(44.3)$ & reference & & & \\
\hline & Yes & $50(65.8)$ & $0.41(0.23-0.74)$ & $<0.001$ & & \\
\hline \multirow[t]{2}{*}{ Current contraception use } & No & $47(58.8)$ & $2.05(1.16-3.63)$ & 0.01 & & \\
\hline & Yes & $52(40.9)$ & reference & & & \\
\hline \multirow[t]{2}{*}{ Sexual intimate partner violence } & No & $70(42.9)$ & reference & & reference & \\
\hline & Yes & $29(65.9)$ & $2.57(1.28-5.15)$ & 0.01 & $2.28(1.03-5.03)$ & 0.04 \\
\hline \multirow[t]{2}{*}{ Sexual intercourse within the past one year } & No & $25(67.6)$ & $2.70(1.27-5.73)$ & 0.01 & $2.89(1.20-6.93)$ & 0.02 \\
\hline & Yes & $74(43.5)$ & reference & & reference & \\
\hline \multirow{2}{*}{ Condom use in the last sexual intercourse } & No & $65(54.6)$ & $1.91(1.09-3.35)$ & 0.02 & & \\
\hline & Yes & $34(38.6)$ & reference & & & \\
\hline Comprehensive knowledge about & No & $35(63.6)$ & $2.41(1.27-4.55)$ & 0.01 & $2.26(1.13-4.54)$ & 0.02 \\
\hline HIV transmission & Yes & $64(42.1)$ & reference & & reference & \\
\hline
\end{tabular}

Notes: $\mathrm{SQoL}=$ Sexual Quality of Life, $\mathrm{cOR}=$ Crude Odds Ratio, $\mathrm{aOR}=$ Adjusted Odds Ratio.

ing:

"When my husband revealed his HIV infection, I did

not want to have intercourse with him anymore".

Five women thought their low sexual desire was associated with aging and described how they had lost interest in sexual activities due to not enjoying the intimacy involved anymore. Meanwhile, eight also described not understanding what sexual pleasure was and have never talked about such with a partner. However, others described the need and/or pressure to focus on the importance of providing pleasurable services to their partner. Lia, a 23-year-old housewife, explained:

"I never known what sexual enjoyment is yet and I feel satisfied only because my husband feels happy about $i t$ ".

Theme 2. Factors influencing the sexual quality of life Sub-theme 2.1. HIV-related concerns

Some women indicated HIV related factors, such as low immunity and commencing on ART, had changed their interest in sexual activities and influenced their personal ability to maintain a satisfying relationship with the partner.

"Yes, when my health dropped, my sexual desire de- creased significantly... that's when my CD4 is very low”. (Ratu, 38-year-old divorcee)

Another woman, Yaya, a 23-year-old housewife, affirmed sexual life's disappointment since being diagnosed with HIV, primarily due to concern about the risk of infecting the partner, which had never had an HIV test. Also, it revealed poor personal understanding of safe sexual practices that constricted the sexual activities and enjoyment experienced in the relationship, saying:

"I forbid my current husband to do.... to my genitalia with his mouth and not to insert his finger inside my vagina. I feared having a long kiss with him. Recently, I rarely had the climax."

Sub-theme 2.2. Inability to talk about sexuality

During the interviews, most participants demonstrated embarrassment and shyness talking about their sexual life by speaking in low voices and giving short answers. Some showed a lack of interest in discussing this topic in-depth. Furthermore, many remarked on how challenging and 'taboo' it was talking to other people about sexual topics and the associated issues, particularly with their partner/s. However, after gaining trust with the interviewer, some women, including those that had never spo- 
Table 5. Demographic Characteristics of the Interview Participants $(n=30)$

\begin{tabular}{|c|c|c|c|c|c|c|}
\hline Pseudonym & Age (years) & City/District & Religion & Last Education & Occupation & Marital Status \\
\hline Adel & 31 & Tangerang City & Islam & Senior high school & Employed & Married \\
\hline Sarah & 39 & Tangerang City & Islam & Senior high school & Housewife & Married \\
\hline Riri & 40 & South Tangerang City & Islam & University & Employed & Married \\
\hline Ade & 35 & Tangerang City & Islam & Senior high school & Employed & Married \\
\hline Eka & 32 & Tangerang City & Islam & Senior high school & Employed & Divorced/separated \\
\hline Widy & 33 & Tangerang City & Islam & University degree & Employed & Married \\
\hline Ani & 34 & Tangerang City & Islam & Senior high school & Employed & Married \\
\hline Kun & 38 & Tangerang City & Islam & Senior high school & Employed & Widowed \\
\hline Niull & 33 & Tangerang City & Islam & Senior high school & Employed & Married \\
\hline Roma & 41 & Tangerang City & Islam & Senior high school & Employed & Married \\
\hline Arum & 33 & Tangerang District & Islam & Senior high school & Housewife & Married \\
\hline Indri & 29 & South Tangerang City & Islam & Senior high school & Employed & Never married \\
\hline Yaya & 23 & Tangerang District & Islam & Senior high school & Housewife & Married \\
\hline Mercy & 33 & South Tangerang City & Islam & Junior high school & Employed/Ex-CSW* & Married \\
\hline Lia & 23 & Tangerang District & Islam & Junior high school & Housewife & Married \\
\hline Yulia & 22 & South Tangerang City & Islam & Junior high school & Unemployed/Ex-CSW & Never married \\
\hline Ratu & 38 & South Tangerang City & Islam & University & Employed & Divorced/separated \\
\hline Dian & 26 & Tangerang City & Islam & Senior high school & Employed & Married \\
\hline Sys & 24 & Tangerang District & Catholic & Senior high school & Unemployed & Never married \\
\hline $\mathrm{Nia}$ & 27 & Cilegon City & Islam & Junior high school & Housewife & Married \\
\hline Yati & 34 & Cilegon City & Islam & Primary school & Employed & Married \\
\hline Clara & 42 & Cilegon City & Islam & Primary school & Employed & Divorced/separated \\
\hline Anita & 23 & Cilegon City & Islam & Junior high school & Unemployed & Divorced/separated \\
\hline Rizky & 31 & Serang City & Islam & Senior high school & Housewife & Married \\
\hline Iyah & 30 & Serang City & Islam & Senior high school & Employed & Married \\
\hline $\mathrm{Da}$ & 33 & Pandeglang District & Islam & University & Housewife & Divorced/separated \\
\hline Neng & 25 & Serang District & Islam & University & Housewife & Married \\
\hline Iin & 33 & Cilegon City & Islam & Primary school & Employed/CSW & Divorced/separated \\
\hline
\end{tabular}

Note: *Ex-CSW: Had history of working as CSW; Comission on the Status of Women

ken openly before on personal sexual life, eagerly talked about their sexual relationships. For example, Sarah mentioned,

"I have never told my current husband if I have less desire to sexual activities. I just follow what he wants... feel shy of talking about it [sex].”.

Sub-theme 2.3. An obligation to serve a husband

Sexual intimacy was described as the wife's obligation to their husband and also considered an important part of keeping peace in the relationship, but not necessarily fulfilling women's sexual needs. They had to 'serve' their husband since refusing to have sexual intercourse is a sin. Fifteen women said they had never experienced or already lost sexual pleasure after discovering being infected with HIV. They also declared it was the norm to put aside their desire for sexual intimacy and satisfaction. This belief was a part of the religious perspectives learned from family, friends, teachers, or social media. Kun, a 38-year-old widow, shared a personal story, saying:

"I never knew what climax is from my husband. What

I knew was that as a wife, I must serve my husband."

Sub-theme 2.4. Abusive partner

Almost half of the participants experienced IPV be- fore and/or after their HIV diagnosis. In all cases, the women had not reported the incidents and described experiences of repeated violence. They considered their IPV experiences related to jealousy, arguing, and refusal of their partner's sexual invitation. Some participants that had such experience assumed it was due to the HIV diagnosis and treatment, often exacerbated by their partner's alcohol consumption. Two participants reported successfully leaving their abusive partner; however, most described the inability to make this decision. No one said the IPV incident to the legal authorities or sought help from health care professionals. Yaya sexual IPV experience was stating:

"He forced me to serve him and did it roughly. I told

him that I did not want it, but he did not listen."

Sub-theme 2.5. Peer group influences

Based on the results, most of the interview participants find it important to partake along with their partners in peer support activities, such as seminars about women's rights and IPV, because of being taught how to communicate personal desires and also respect each other's sexual rights. After understanding the women's SRH rights, they were more open in talking about their sexual desires and satisfaction. The partners were also 
Table 6. Convergent Themes

\begin{tabular}{|c|c|c|}
\hline \multirow{2}{*}{ Convergent Theme } & \multicolumn{2}{|l|}{ Key Finding } \\
\hline & Quantitative Variable & Qualitative Theme \\
\hline Unsatisfactory sexual life & $\begin{array}{l}74.4 \% \text { thought sex was an enjoyable part of } \\
\text { their overall life. } \\
69.1 \% \text { had lost pleasure in their sex life } \\
66.7 \% \text { felt angry and } 64.7 \% \text { were depressed } \\
\text { about their sexual life } \\
64.3 \% \text { tried to avoid sexual activity. } \\
47.8 \% \text { had low sexual life quality }\end{array}$ & Low sexual desire and satisfaction \\
\hline Personal factor & $\begin{array}{l}\text { Short-term of Antiretroviral theraphy } \\
\text { Poor knowledge of HIV-transmission } \\
\text { Housewife/unemployed } \\
\text { Early age of first sexual encounter }\end{array}$ & $\begin{array}{l}\text { HIV-related concerns: } \\
\text { Low immunity } \\
\text { Antiretroviral theraphy } \\
\text { Fear of transmitting HIV }\end{array}$ \\
\hline Social factor & $\begin{array}{l}\text { Sexual intimate partner violence } \\
\text { Living with extended family }\end{array}$ & $\begin{array}{l}\text { Abusive partner } \\
\text { Peer group influences }\end{array}$ \\
\hline $\begin{array}{l}\text { Culture norm and religious belief } \\
\text { factors }\end{array}$ & & $\begin{array}{l}\text { Inability to talk about sexuality } \\
\text { An obligation to serve a husband }\end{array}$ \\
\hline
\end{tabular}

more respectful of the right to refuse sexual invitations in certain circumstances. Ani, a 34-year-old married woman that began attending SRH seminars with the partner for PLHIV, saying:

"He starts to understand me. For example, it is okay if I

do not want it, and he asked me when I want it.".

The similarities and disparities across the survey and interview data suggest overlapping sexual issues occurring within complex, inter-related factors as can be seen in Table 6. It was confirmed that on the whole, the quantitative were consistent with qualitative findings. Even though some differences were identified, there were no contradictions. The convergent theme of unsatisfactory sexual life was consistently supported by the statistics and interview data. Statistically, WLHIV low interest in sex and the associated distress were linked significantly to women's clinical status, working as a housewife, living with extended family, low HIV knowledge, and sexual IPV experience. Meanwhile, qualitatively, their sexual discomfort increased for those prioritizing the partner's sexual desire, while being bound with social norms and personal belief to impede sexual enjoyment and desire.

\section{Discussion}

The mixed-methods study represented the convergence of findings from a survey and qualitative in-depth interviews to identify and measure the multiple factors influencing WLHIV sexual quality of life in Banten Province, Indonesia. While the survey indicated significant personal and social factors associated with sexual quality of life, the in-depth interview described deeper WLHIV SQoL explanation related to its personal, social, and religious-cultural contexts. Furthermore, both indicated predominant individual factors affecting the women's low SQoL were ART, low immunity, and inadequate knowledge or fear of HIV transmission. These findings are consistent with a Morocco study that reported about $70 \%$ of WLHIV respondents had insufficient sexual activity and disorders such as decreased sexual desire and anorgasmia. ${ }^{32}$ Unsatisfactory sexual life postHIV diagnosis has been reported in a review in Muslimmajority countries, which similarly found the reasons were related to ART event, HIV status denial, and fear of transmitting the infection. ${ }^{9,15}$ The present study also linked the sexual dissatisfaction with women's anger and disappointment to their partner that infected them with HIV.

Based on the findings, low SQoL was significantly associated with women's gender roles and work as a housewife or unemployed, while many concealed their sexual desire and prioritized the partner's, particularly husband sexual satisfaction. The women, were predominantly Muslim housewives, have little power or rights to demand sexual pleasure or safer sex due to existing cultural and religious belief. Indonesian culture prevents people from talking openly about SRH-related topics. ${ }^{33}$ The study by Bennett, et al., 34 affirmed the taboo of talking about sexual topics in the country, contributing to women's poor understanding of common SRH problems and preventive measurements to avoid pregnancy, HIV, and other STIs. The women also face religious-cultural difficulties when negotiating safer and satisfying sex practices with their partners. ${ }^{35,36}$

Gender imbalance and patriarchal culture in Indonesia have persistently assigned privileged positions and roles to men to control and sometimes violate women. ${ }^{35,37}$ It is suggested that this continues today and also becomes amplified for WLHIV. Due to financial dependence on partners, many women have limited power 
in their family to request or enforce condom utilization, refuse sex, including sexual practices that place them at increased risk of HIV, unplanned pregnancy and other adverse SRH outcomes, and ultimately to defend their SRH rights. ${ }^{38,39}$ These align with Shahhosseini, et al., ${ }^{40}$ findings that reported low sexual satisfaction among WLHIV with no or low income and poor interpersonal communication skills. Also, many WLHIV described sexual activity as a means to maintain their relationships, not to obtain pleasure. These correspond with Asian cultural beliefs that women should prioritize their duty and obligation for their husbands. ${ }^{41}$ According to similar findings in Bangladesh, women maintained sexual activities only to prevent conflict between partners. ${ }^{42}$ Personal and community values strongly affected the WLHIV participants' sexual wellbeing. Moreover, religious and cultural gender norms and values hindered the ability to voice their sexual needs, as men maintain power to control and violate women. These gender inequalities have stopped many women, including WLHIV, in middle and low-income countries, from achieving their right to a safe and enjoyable sexual life. ${ }^{15,35}$

The interviews suggested women diagnosed over a long time and also involved in peer support activities demonstrated and reported higher levels of SRH literacy and confidence in negotiating their needs and rights. This indicates women's ability to negotiate SRH rights tends to be developed with community peer groups' support. The finding is consistent with the study that stated peer counselling, education, and accompaniment worked successfully in improving WLHIV SRH outcomes. 43,44

This study has several limitations, such as being conducted primarily among WLHIV that accessed treatment in public HIV treatment facilities and Yayasan Kotex Mandiri. Furthermore, the surveyed sample size was relatively small and recruited using a non-probability sampling method. Therefore, this possibly lacks the perspectives of WLHIV that were not engaged in HIV care. The results tend not to be generalizable to WLHIV in rural settings and those not accessing tertiary referral hospitals. Data were self-reported by the participants in relation to issues considered sensitive, which gives rise to potential social desirability bias.

This study's major strength was that the mixed methods not only provided a quantification of sexual life quality but also more detailed information on the influencing factors. It is the first to comprehensively explore quality of sexual life among WLHIV in Indonesia using mixed methods approach. The results provided advanced insights into the socio-cultural factors impacting WLHIV's sexual quality of life. This is useful for informing future SRH health strategies and interventions for the wellness of WLHIV and the women population generally.

\section{Conclusion}

Conclusively, the intersection of personal, social, and cultural factors attributing to women living with HIV experiencing unsatisfactory sexual life was identified. These inter-related factors, such as slow adjustment to HIV infection and treatment, abusive relationships, women's inability to express their sexual needs and to refuse invitations, present significant barriers to achieving healthy life and wellness by WLHIV. The support from their partner, family, peers, health professional, and community tends to offset some of these experiences and are also essential when WLHIV needs to achieve their SRH rights and well-being.

The findings highlighted the need for health systems enabling women to build confidence to voice their sexual needs and advocate personal rights. Support structures, local religious-cultural norms, and public policy are acknowledged and prepared to empower women in meeting their sexual health. Multi-discipline professionals, including sexuality specialists, psychologists, and public health practitioners, need to partner with the WLHIV to develop a health system and network of peer support that mitigates the challenges faced. Free availability of these services to the sufferers and all women at adverse SRH outcomes risk is necessary. Future study needs to develop skill-based interventions that increase women's communication and negotiation skills for safer sex practices and manage the IPV issues among WLHIV.

\begin{abstract}
Abbreviations
aOR: Adjusted Odds Ratio; ART: Antiretroviral Therapy; cOR: Crude Odds Ratio; HIV: Human Immunodeficiency Virus; IDHS: Indonesia Demographic Health Survey; IPV: Intimate partner violence; PLHIV: People living with HIV; PR: Peer Recruiter; SRH: Sexual and Reproductive Health; STI: Sexually Transmitted Infection; SQoL: Sexual Quality of Life; SQoL-F: Sexual Quality of Life-Female; UQ: The University of Queensland; WHQ: Women Health Questionnaire; WLHIV: Women living with HIV.
\end{abstract}

\section{Ethics Approval and Consent to Participate}

Ethical approval was issued by the University of Queensland Human Research Ethical Committee (Approval Number: 2017000354). All individual participants recruited signed the research consent preceding the interview

\section{Competing Interest}

The author declares that there are no significant competing financial, professional, or personal interests that might have affected the performance or presentation of the work described in this manuscript.

\section{Availability of Data and Materials}

All data were stored electronically in the University of Queensland data management system accessible by the authors team only considering 
the topics' sensitiveness, but the information is available upon request.

\section{Authors' Contribution}

DJ initiated the research concept, while LF and JD assisted in developing the final protocol used. In addition, DJ collected the data which were analyzed by DJ, LF, and JD. This manuscript was drafted by DJ, while all authors interpreted the findings, contributed to the revisions, read, and approved the final manuscript.

\section{Acknowledgment}

The authors are grateful to all WLHIV agreed to participate in the survey and interview, and to the peer recruiters, and Yayasan Kotex Mandiri for their collaboration. The authors are also grateful to the Australian Awards and the University of Queensland for the financial support. Besides, this article's contents are solely the responsibility of the authors.

\section{References}

1. Joint United Nations Programme on HIV and AIDS. Global HIV \& AIDS statistics - 2020 fact sheet. Geneva: UNAIDS; 2020.

2. Kementerian Kesehatan Republik Indonesia. Profil kesehatan Indonesia tahun 2019. Jakarta: Kementerian Kesehatan Republik Indonesia; 2020.

3. Kementerian Kesehatan Republik Indonesia. Laporan perkembangan HIV-AIDS triwulan I tahun 2020. Jakarta: Direktorat Jenderal Pencegahan dan Pengendalian Penyakit, Kementerian Kesehatan Republik Indonesia; 2020.

4. Khosla R, Van Belle N, Temmerman M. Advancing the sexual and reproductive health and human rights of women living with HIV: a review of $\mathrm{UN}$, regional and national human rights norms and standards. Journal of the International AIDS Society. 2015; 18 (Suppl 5): 20280.

5. United Nations Population Fund. Sexual and reproductive health. Washington DC.: UNFPA; 2021.

6. World Health Organization. Consolidate guideline on sexual and reproductive health and rights of women living with HIV. Geneva: World Health Organization; 2017.

7. Adekanle DA, Olowookere SA, Adewole AD, Adeleke NA, AbioyeKuteyi EA, Ijadunola MY. Sexual experiences of married HIV positive women in Osogbo, Southwest Nigeria: role of inappropriate status disclosure. BMC Women's Health. 2015; 15: 6.

8. Maeri I, El Ayadi A, Getahun M, Charlebois E, Akatukwasa C, Tumwebaze D, et al. "How can I tell?" Consequences of HIV status disclosure among couples in Eastern African communities in the context of an ongoing HIV "test-and-treat" trial. AIDS care. 2016; 28 Suppl 3: 59-66.

9. Closson EF, Mimiaga MJ, Sherman SG, Tangmunkongvorakul A, Friedman RK, Limbada M, et al. Intimacy versus isolation: a qualitative study of sexual practices among sexually active HIV-infected patients in HIV care in Brazil, Thailand, and Zambia. PloS one. 2015; 10 (3): e0120957.

10. Kaida A, Carter A, de Pokomandy A, Patterson S, Proulx-Boucher K, Nohpal A, et al. Sexual inactivity and sexual satisfaction among women living with HIV in Canada in the context of growing social, legal and public health surveillance. Journal of the International AIDS
Society. 2015; 18 (Suppl 5): 20284.

11. World Health Organization. Sexual health, human rights and the law. Geneva: World Health Organization; 2015.

12. Chakraborty H, Patted S, Gan A, Islam F, Revankar A. Determinants of Intimate Partner Violence Among HIV-Positive and HIV-Negative Women in India. J Interpers Violence. 2016; 31 (3): 515-30.

13. Chin YM. Does HIV increase the risk of spousal violence in subSaharan Africa?. Journal of health economics. 2013; 32 (5): 997-1006.

14. Okareh OT, Akpa OM, Okunlola JO, Okoror TA. Management of conflicts arising from disclosure of HIV status among married women in southwest Nigeria. Health Care for Women International. 2015; 36 (2): $149-60$

15. Juliastuti D, Dean J, Fitzgerald L. Sexual and reproductive health of women living with HIV in Muslim-majority countries: a systematic mixed studies review. BMC International Health and Human Rights. 2020; 20 (1): 5.

16. Creswell JW. Research design: qualitative, quantitative, and mixedmethods approaches. Sage Publications; 2013.

17. Kaur M. Application of mixed method approach in public health research. Indian Journal of Community Medicine: Official Publication of Indian Association of Preventive \& Social Medicine. 2016; 41 (2): 937.

18. Shorten A, Smith J. Mixed methods research: expanding the evidence base. Evidence Based Nursing. 2017; 20 (3): 74-5.

19. Creswell JW, Plano Clark VL. Designing and conducting mixed methods research. Sage Publications. 2017.

20. Dinas Kesehatan Provinsi Banten. Profil kesehatan Provinsi Banten 2015 Serang, Banten; 2016.

21. Reaves CC. Quantitative research for the behavioral sciences. New York: John Wiley \& Sons, Inc.; 1992.

22. Statistics Indonesia, National Population and Family Planning Board, Kementrian Kesehatan Republik Indonesia, ICF International. Indonesia demographic and health survey 2012. Jakarta, Indonesia: BPS, BKKBN, Kemenkes, ICF International; 2013.

23. Symonds T, Boolell M, Quirk F. Development of a questionnaire on sexual quality of life in women. Journal of Sex \& Marital Therapy. 2005; 31 (5): 385-97.

24. Pallant J. SPoS survival manual: a step by step guide to data analysis using IBM SPSS. 6th ed. London, UK: McGraw-Hill Education; 2016.

25. Ranganathan P, Pramesh CS, Aggarwal R. Common pitfalls in statistical analysis: logistic regression. Perspectives in Clinical Research. 2017; 8 (3): 148-51.

26. Boateng GO, Neilands TB, Frongillo EA, Melgar-Quiñonez HR, Young SL. Best practices for developing and validating scales for health, social, and behavioral research: a primer. Front Public Health. 2018; 6: 149 .

27. Brown KM, Elliott SJ, Leatherdale ST, Robertson-Wilson J. Searching for rigour in the reporting of mixed methods population health research: a methodological review. Health Education Research. 2015; 30 (6): 811-39.

28. Braun V, Clarke V. Using thematic analysis in psychology. Qualitative Research in Psychology. 2006; 3 (2): 77-101.

29. Padgett D. Qualitative and mixed methods in public health. Thousand Oaks, California: Sage Publications, Inc; 2012. 
30. Curry LA, Nembhard IM, Bradley EH. Qualitative and mixed methods provide unique contributions to outcomes research. Circulation. 2009; 119 (10): 1442-52.

31. Guetterman TC, Fetters MD, Creswell JW. Integrating quantitative and qualitative results in health science mixed methods research through joint displays. Annals of Family Medicine. 2015; 13 (6): 55461.

32. El Fane M, Bensghir R, Sbai S, Chakib A, Kadiri N, Ayouch A, et al. Quality of sexual life for people living with HIV (PLWHA). Sexologies. 2011; 20 (3): 158-62.

33. Utomo ID, McDonald P. Adolescent Reproductive Health in Indonesia: Contested Values and Policy Inaction. Studies in family planning. 2009; 40 (2): 133-46.

34. Bennett LR. Zina and the enigma of sex education for Indonesian Muslim youth. Sex Education. 2007; 7 (4): 371-86.

35. Amin A. Addressing gender inequalities to improve the sexual and reproductive health and wellbeing of women living with HIV. Journal of the International AIDS Society. 2015; 18 (6S5): 20302.

36. Bennett LR, Davies SG. Sex and sexualities in contemporary Indonesia: sexual politics, health, diversity and representations. Routledge; 2014.

37. Aisyah S, Parker L. Problematic conjugations: women's agency, marriage and domestic violence in Indonesia. Asian Studies Review. 2014; 38 (2): 205-23.

38. Jacubowski N. Marriage is not a safe place: heterosexual marriage and
HIV-related vulnerability in Indonesia. Culture, Health and Sexuality. 2008; 10 (1): 87-97.

39. Puradiredja DI, Coast E, Sear R. Why do female sex workers in Indonesia not use condoms?: a mixed methods study of the heterogeneous contexts of condom use. European Population Conference; Barcelona, Spain: LSE Research Online; 2008.

40. Shahhosseini Z, Gardeshi ZH, Pourasghar M, Salehi F. A review of affecting factors on sexual satisfaction in women. Materia Socio-Medica. 2014; 26 (6): 378-81.

41. United Nations Development Programme, WAP+, APN+, Unzip the Lips. Discussion paper: linkages between violence against women and HIV in Asia and the Pacific. Bangkok: UNDP; 2013.

42. Anwar N, Khan SI. Sexual life after HIV infection: an exploratory study among HIV positive adult males and females in Dhaka, Bangladesh. International Journal of Interdisciplinary Social Sciences. 2010; 5( 2): 589-602.

43. Richter L, Rotheram-Borus MJ, Van Heerden A, Stein A, Tomlinson M, Harwood JM, et al. Pregnant women living with HIV (WLH) supported at clinics by peer WLH: a cluster randomized controlled trial. AIDS and Behavior. 2014; 18 (4): 706-15.

44. Robinson JL, Narasimhan M, Amin A, Morse S, Beres LK, Yeh PT, et al. Interventions to address unequal gender and power relations and improve self-efficacy and empowerment for sexual and reproductive health decision-making for women living with HIV: a systematic review. PloS one. 2017; 12 (8): e0180699-e. 